\title{
Structural Behavior of SFRC Beams strengthened with GFRP Laminates: An Experimental and Analytical Investigation
}

\author{
M.Mariappan $^{1}{ }^{*}$, P.N.Raghunath ${ }^{2}$, M.Sivaraja ${ }^{3}$. \\ ${ }^{I}$ Department of Civil Engineering, Adhiparasakthi Engineering College; ${ }^{2}$ Annamalai University, Chidambaram, \\ India; ${ }^{3}$ Department of Civil Engineering, N.S.N. College of Engg. \& Tech., Karur, India.
}

\begin{abstract}
This paper presents the experimental results of a reinforced concrete beams $(R C)$ strengthened with internal steel fibers (SF) and external glass fiber reinforced polymer laminates (GFRP). The research work studied the load carrying capacity, deformation, crack width and ductility of the reinforced concrete beams strengthened with different steel fiber ratios and steel fiber reinforced concrete beams strengthened with three different glass fiber reinforced polymer laminates of two different thickness. The experimental results clearly shows that incorporating steel fibers in to the reinforced concrete beams reduced the crack width and distribute the crack evenly and also increases the bonding between tension face of the beam with glass fiber reinforced polymer laminates. The results also shows that glass fiber reinforced polymer laminates strengthened steel fiber reinforced concrete beams increases the flexural strength and ductility as compared with unstrengthened counterpart. In addition to this experimental work, theoretical calculations were done to find the ultimate load carrying capacity of the beam tested, and also compared with the experimental results.
\end{abstract}

Key words: RC, FRC, GFRP, SFRC, Ductility

\footnotetext{
*Author for correspondence: mariappan.m2009@gmail.com
} 


\section{INTRODUCTION}

Many research and development in the reinforced concrete structural elements using high performance materials has progressed significantly in recent years. Previous researchers conducted experimental and analytical investigations on debonding of hybrid FRPs for flexural strengthening of RC beams ${ }^{[1]}$. One or two layers of CFRP or GFRP sheets were used for strengthening purpose ${ }^{[13,14]}$. The test results shows that adding the existing three-point bending test method for a small $\mathrm{RC}$ beam, debonding failure can be induced in the RC beams strengthened with FRPs $^{[15,19]}$. The modifications are performed by including a saw-cut in the middle of the beam span and adding a reinforcing bar to prevent shear failure ${ }^{[8,9]}$. The experimental results show that the beam strengthened with stiffer and thinner layers of FRPs have higher debonding strengths than the beams strengthened with less stiff and the thicker layers of FRPs ${ }^{[13,20]}$. Therefore, the debonding level of the hybrid FRP plates is more influenced by the thickness of the strengthening materials than by its stiffness ${ }^{[4,5]}$. The debonding strength is also influenced by the arrangement of layers and the higher debonding strengths were achieved when a layer of CFRP is attached to the concrete prior to a GFRP layer ${ }^{[6,7]}$. Previous researcher ${ }^{[2]}$ conducted experimental research on the fatigue and post-fatigue static behaviour of reinforced concrete beams strengthened with glass or carbon fiber reinforced polymer sheets placed either vertically or obliquely. The test results have shown that externally bonded CFRP or GFRP to the lateral and bottom faces of a beam can increase the first crack load and ultimate strength greatly, arrest concrete crack extension and enhance the rigidity of strengthened beams ${ }^{[10,11]}$. The CFRP strengthened beam has the highest ultimate strength but the lowest deflection and the diagonal GFRP reinforcing arrangement is more effect than the vertical arrangement in enhancing the shear strength and stiffness ${ }^{[12]}$. From experimentally investigated the performance of RC beam strengthened with externally bonded FRP composites ${ }^{[3]}$, the response of control and strengthened beams were compared and efficiency and effectiveness of different schemes were evaluated. It was observed that tension side bonding of CFRP sheets with U-shaped end anchorages is very efficient in flexural strengthening, whereas bonding the inclined CFRP strips to the side of RC beams are very effective in improving the shear capacity of beams ${ }^{[16]}$.

This paper focuses on the study on structural performance of reinforced concrete beams with steel fibers of different ratios and steel fiber reinforced concrete beams with GFRP laminates of different types and different thickness. An analytical study is also involved to validate the experimental results using ACI 440-2R equation $[17,18]$

\section{EXPERIMENTAL STUDY}

\section{MATERIALS}

The concrete used for all beam specimens had a compressive strength of $24 \mathrm{MPa}$. The concrete consisted of $370 \mathrm{~kg} / \mathrm{m} 3$ of ordinary Portland cement, $584.6 \mathrm{~kg} / \mathrm{m} 3$ of fine aggregate, $701.5 \mathrm{~kg} / \mathrm{m} 3$ of coarse aggregate, $467.68 \mathrm{~kg} / \mathrm{m} 3$ of medium aggregate, 0.36 water/cement ratio and $0.8 \%$ of hyper plasticizer. The reinforcement of high yield strength deformed bars of characteristic strength $456 \mathrm{MPa}$ were used for the longitudinal reinforcement. The lateral ties consisted of mild steel bars of yield strength 300MPa. The specimens were provided with $8 \mathrm{~mm}$ diameter stirrups at $150 \mathrm{~mm}$ spacing. 


\section{Steel Fibres}

The steel fibres used were Dramix steel fibres. The physical and mechanical properties of steel fibres are presented in Table 2.

\section{Glass Fibre Reinforced Polymer}

Glass fibres reinforced polymer having the following configurations were used for the investigation.

i. Chopped Strand Mat (CSM)

ii. Uni-Directional Cloth (UDC)

iii.Woven Roving (WR)

The glass fibre reinforced polymer fabrics were applied on the soffit of the beam specimens using epoxy adhesive. The physical and mechanical properties of GFRP laminates are presented in Table 1 .

\section{BEAM DETAILS}

Twenty two RC rectangular beam specimens having $150 \mathrm{~mm} \times 250 \mathrm{~mm}$ crosssection and $3000 \mathrm{~mm}$ length were cast for the present research work. Longitudinal steel ratio adopted for the beam specimen was $0.603 \%$ ( 2 bars, $12 \mathrm{~mm}$ diameter). 2-legged $8 \mathrm{~mm}$ diameter shear stirrups were provided at $125 \mathrm{~mm} \mathrm{c} / \mathrm{c}$, in order to avoid any shear failure and ensure flexural action of beams up to failure. The detailing of internal reinforcement is shown through Fig.1. Details of the twenty two specimens prepared for experimental work are presented in Table 3. The beams had three different fibre volume fractions and were laminated with GFRP plates of $3 \mathrm{~mm}$ and $5 \mathrm{~mm}$ thickness. The fibres in GFRP also varied in their configuration, viz., Woven roving (WR), Chopped Strand Mat (CSM) and UniDirectional Cloth (UDC).

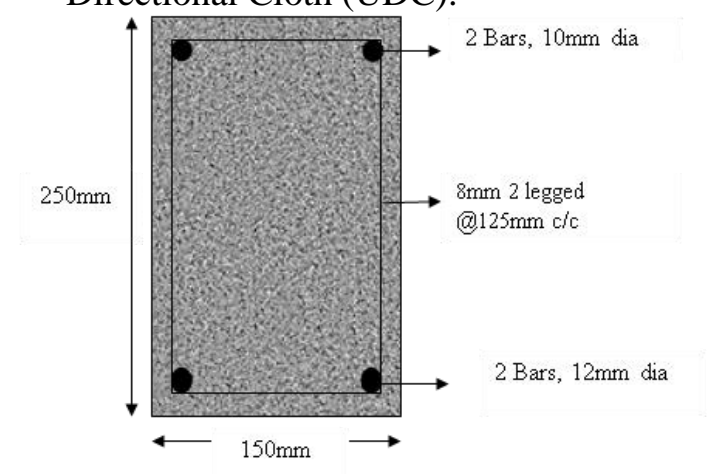

Fig.1 Reinforcement Details of Beam Specimen

Table 1 - Properties GFRP Laminates

\begin{tabular}{|c|c|c|c|c|c|}
\hline $\begin{array}{l}\text { Sl. } \\
\text { No. }\end{array}$ & $\begin{array}{l}\text { Type of Fibre } \\
\text { in GFRP }\end{array}$ & 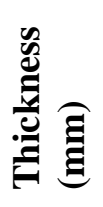 & 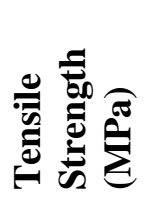 & 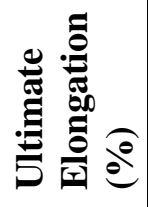 & 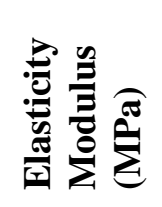 \\
\hline 1. & $\begin{array}{l}\text { Chopped } \\
\text { Strand Mat }\end{array}$ & 3 & 126.20 & 1.69 & 7467.46 \\
\hline 2. & $\begin{array}{l}\text { Chopped } \\
\text { Strand Mat }\end{array}$ & 5 & 156.00 & 1.37 & 11386.86 \\
\hline 3. & $\begin{array}{l}\text { Uni- }^{-} \\
\text {Directional } \\
\text { Cloth }\end{array}$ & 3 & 446.90 & 3.02 & 13965.63 \\
\hline
\end{tabular}




\begin{tabular}{|c|c|c|c|c|c|}
\hline $\begin{array}{l}\text { Sl. } \\
\text { No. }\end{array}$ & $\begin{array}{l}\text { Type of Fibre } \\
\text { in GFRP }\end{array}$ & 昜 & 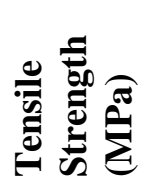 & 总总 & 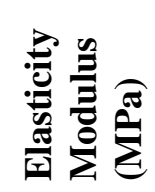 \\
\hline 4. & $\begin{array}{l}\text { Uni- } \\
\text { Directional } \\
\text { Cloth }\end{array}$ & 5 & 451.50 & 2.60 & 17365.38 \\
\hline 5. & $\begin{array}{l}\text { Woven } \\
\text { Rovings }\end{array}$ & 3 & 147.40 & 2.15 & 6855.81 \\
\hline 6. & $\begin{array}{l}\text { Woven } \\
\text { Rovings }\end{array}$ & 5 & 178.09 & 1.98 & 8994.44 \\
\hline
\end{tabular}

Table 2 - Properties Steel fibres

\begin{tabular}{|c|c|}
\hline Fibre Properties & Steel Fibre details \\
\hline Length $(\mathrm{mm})$ & 30 \\
\hline Shape & Hooked at ends \\
\hline Size/Diameter $(\mathrm{mm})$ & $0.5 \mathrm{~mm}$ \\
\hline Aspect Ratio & 60 \\
\hline Density $\left(\mathrm{kg} / \mathrm{m}^{3}\right)$ & 7850 \\
\hline Specific Gravity & - \\
\hline Young's Modulus $(\mathrm{GPa})$ & 210 \\
\hline Tensile strength $(\mathrm{MPa})$ & 532 \\
\hline
\end{tabular}

\section{TEST SETUP}

All the beams were tested under four point- bending in a loading frame of $500 \mathrm{kN}$ capacity. The beams were supported on hinge at one end and roller at the other end. The details of the test set-up are shown in Fig. 2. The beams had $100 \mathrm{~mm}$ bearing on both ends, resulting in a test span of $2800 \mathrm{~mm}$. Two-point loads were applied through a spreader beam. The deflections were measured at mid-span and at load points using mechanical dial gauges of $0.01 \mathrm{~mm}$ accuracy. Two dial gauges were mounted on the compression face of the specimen over supports to measure slope at both ends. The deflection at ultimate load level was also measured using a specially designed mechanical dial gauge. The surface strains at extreme fibres were measured using a Demec gauge. The crack widths were measured using a crack detection microscope with a least count of $0.02 \mathrm{~mm}$. The cracks were identified by carefully observing the concrete surface through a magnifying glass. Crack development and propagation was monitored during the process of testing. All the above measurements were taken at different load levels until failure

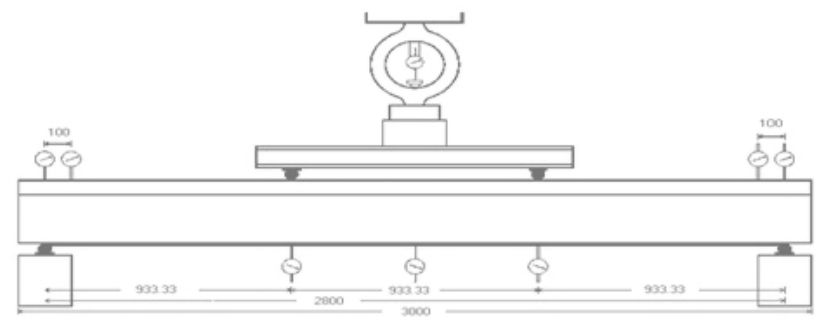

All dimensions in ' $m m$ '

Fig. 2 Details of Instrumentation 
SFRC Beams strengthened with GFRP Laminates

Table 3 - Specimen Details

\begin{tabular}{|c|c|c|c|c|}
\hline \multirow{2}{*}{ 节 } & \multirow{2}{*}{ 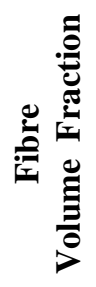 } & \multirow{2}{*}{ 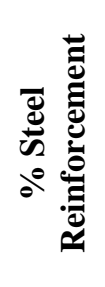 } & \multicolumn{2}{|c|}{ GFRP Laminate } \\
\hline & & & Type & Thickness \\
\hline $\mathrm{CB}$ & - & 0.603 & - & - \\
\hline $0.5 \mathrm{SF}$ & 0.5 & 0.603 & - & - \\
\hline $0.5 \mathrm{SF}-3 \mathrm{UDC}$ & 0.5 & 0.603 & UDC & 3 \\
\hline $0.5 \mathrm{SF}-5 \mathrm{UDC}$ & 0.5 & 0.603 & UDC & 5 \\
\hline $0.5 \mathrm{SF}-3 \mathrm{WR}$ & 0.5 & 0.603 & WR & 3 \\
\hline $0.5 \mathrm{SF}-5 \mathrm{WR}$ & 0.5 & 0.603 & WR & 5 \\
\hline $0.5 \mathrm{SF}-3 \mathrm{CSM}$ & 0.5 & 0.603 & CSM & 3 \\
\hline 0.5SF-5CSM & 0.5 & 0.603 & CSM & 5 \\
\hline $1.0 \mathrm{SF}$ & 1.0 & 0.603 & - & - \\
\hline 1.0SF-3UDC & 1.0 & 0.603 & UDC & 3 \\
\hline 1.0SF-5UDC & 1.0 & 0.603 & UDC & 5 \\
\hline 1.0SF-3WR & 1.0 & 0.603 & WR & 3 \\
\hline 1.0SF-5WR & 1.0 & 0.603 & WR & 5 \\
\hline 1.0SF-3CSM & 1.0 & 0.603 & CSM & 3 \\
\hline 1.0SF-5CSM & 1.0 & 0.603 & CSM & 5 \\
\hline $1.5 \mathrm{SF}$ & 1.5 & 0.603 & - & - \\
\hline 1.5SF-3UDC & 1.5 & 0.603 & UDC & 3 \\
\hline 1.5SF-5UDC & 1.5 & 0.603 & UDC & 5 \\
\hline 1.5SF-3WR & 1.5 & 0.603 & WR & 3 \\
\hline 1.5SF-5WR & 1.5 & 0.603 & WR & 5 \\
\hline 1.5SF-3CSM & 1.5 & 0.603 & CSM & 3 \\
\hline 1.5SF-5CSM & 1.5 & 0.603 & CSM & 5 \\
\hline
\end{tabular}

\section{RESULTS AND DISCUSSION}

The results of experimental investigation carried out on twenty two beams which include, control beam, steel fibre reinforced concrete beams and GFRP strengthened steel fibre reinforced concrete beams are presented in this chapter. The study parameters considered for this research work included service load, deflection at service load, yield load, deflection at yield load, ultimate load, ultimate load deflection, deflection ductility, curvature ductility, deflection ductility ratio and crack width. 


\section{Effect of GFRP plating on strength}

The experimental ultimate loads were obtained corresponding to the stage of loading beyond which the beam would not sustain additional deformation at the same load intensity. The increase in ultimate load was found to be $24.06 \%$ with $1.5 \%$ fibre content when compared to the reference beam. The strengthened beams exhibit an increase of $39.82 \%$ with 5mmCSMGFRP, $47.98 \%$ with 5mmWRGFRP and $61.01 \%$ with 5mmUDCGFRP. It can be inferred from the test results Fig.3 that increase in fibre content has noticeable effect on the ultimate loads.

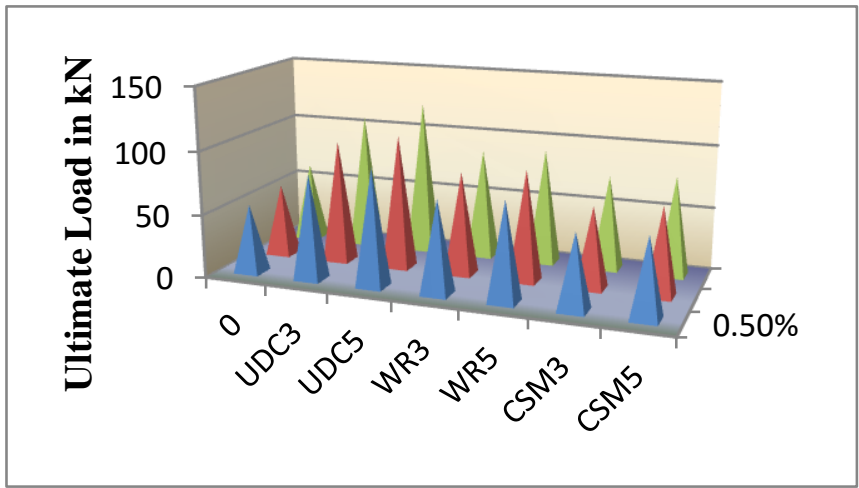

Fig. 3 Effect of GFRP Plating on Ultimate Loads

\section{Effect of GFRP plating on deflection}

The deflection characteristics of the reinforced concrete beams improved much with the addition of fibres. These influences were more pronounced for fibre reinforced concrete beams strengthened with GFRP laminates.

Deflection of a beam primarily depends on the loading, span, moment of inertia of the section and elasticity modulus of concrete. Bonding of GFRP laminates to the soffit of a beam results in an increase in cross-sectional area and stiffness. This increase in stiffness influences the deflection behaviour of the plated beams during pre-cracking, cracking and post-cracking stages. From the test results, it can be observed that the steel fibre reinforced concrete beams exhibit increase in deflection with increase of fibre content at ultimate load level when compared to the reference beam. The increase in ultimate deflection was found to be $29.15 \%$ with $1.5 \%$ fibre content when compared with the reference beam. The increase in ultimate deflection was found to be $51.40 \%, 55.85 \%$ and $60.15 \%$ respectively with $1.5 \%$ fibre content for beams strengthened with 5mmCSMGFRP, 5mmWRGFRP and 5mmUDCGFRP when compared with the reference beam. The effect of GFRP laminates on deflections at various load levels are shown in Figs. 4 to 6. 
SFRC Beams strengthened with GFRP Laminates

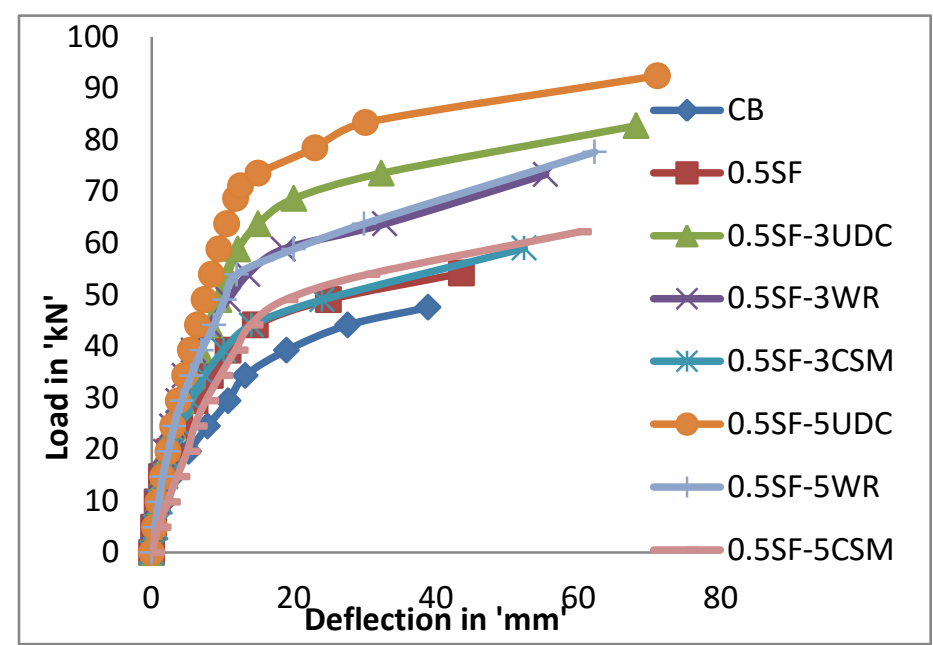

Fig. 4 Load - Deflection Response of Beams with 0.5\% Fibre Volume Fraction

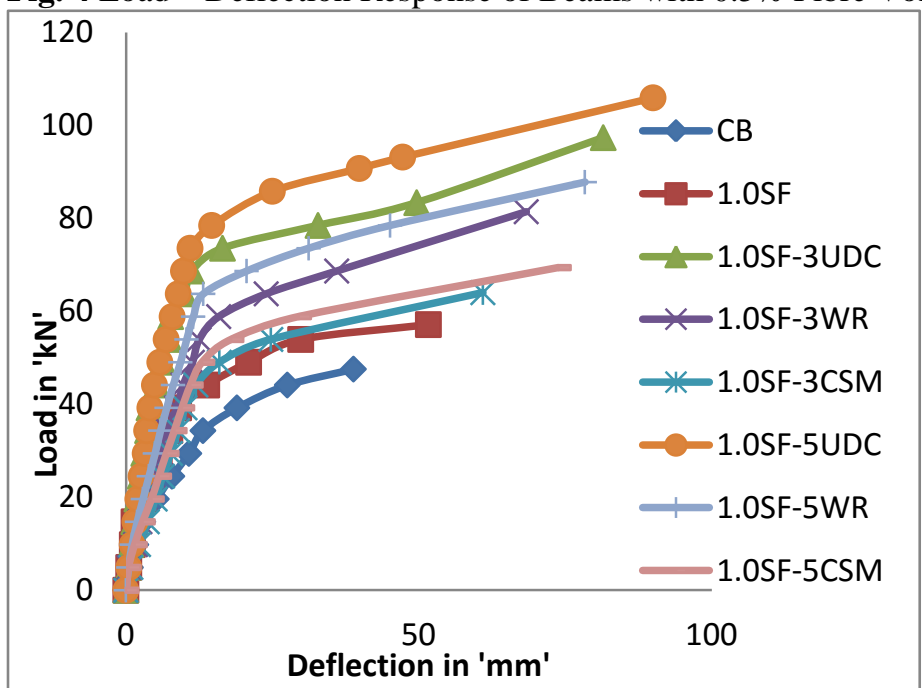

Fig. 5 Load - Deflection Response of Beams with 1.0\% Fibre Volume Fraction

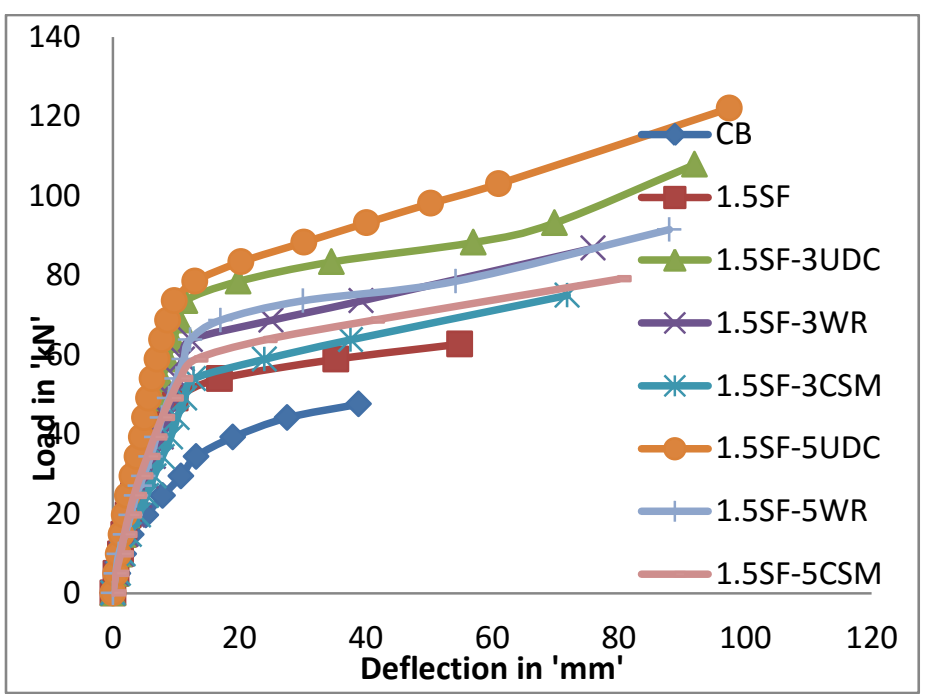

Fig. 6 Load - Deflection Response of Beams with 1.5\% Fibre Volume Fraction

The load-deflection response of reference specimens exhibits three regions of behaviour. At low load levels, the steel fibre reinforced concrete beam stiffness is relatively high indicating that the concrete behaves in a linear elastic manner. As

Braz. Arch. Biol. Technol. v.59: e16161071 Jan/Dec 2016 Spec Iss 2 
the load increases, the extreme fibre stresses in bending increase until the tensile strength of concrete is reached. This causes flexural cracking initially in the constant moment region. Flexural cracking causes a marked reduction in stiffness as shown by a sudden change of gradient in the response.

After the concrete cracks in the tension zone, a greater portion of the tensile component of the bending moment is carried by the steel reinforcement. As the beam rotation increases further, the rebar stress increases throughout the constant moment zone. Eventually, the yield stress of steel is reached at one or more points. Such loss of material stiffness results in a reduction in the overall stiffness of the beam and the ability of the section to support the tensile component of the bending moment is reduced. This is shown by the second marked change in gradient of the response.

Flexural cracks formed in the constant moment zone extend vertically upwards and become progressively wide as the load is increased. Cracks are also initiated in the shear spans of the beam with increased loads. The final failure of the beam is characterized by large strains in the steel reinforcement \& substantial deflection near collapse accompanied by extensive cracking. An overall evaluation of the load-deflection curves indicate that steel fiber reinforced concrete beams strengthened with GFRP laminates exhibit higher load carrying capacity and ductility.

The load-deflection response of the plated beams is similar to unplated beams but with several significant differences. The pre-cracking stiffness is identical for both plated and unplated beams. This is to be expected as the entire section is effective and the plate has relatively little effect on the moment of inertia and hence the flexural rigidity of the section.

The post-cracking stiffness of the plated beams is significantly higher than that of the unplated beams. After cracking, when the concrete beneath the neutral axis becomes ineffective, the addition of the plate causes a significant increase in the moment of inertia and hence the flexural rigidity of the strengthened beam. The plate is positioned most advantageously in terms of increasing the beam stiffness when bonded to the soffit of the beam as its lever arm to the neutral axis is the maximum. Also the plate provides a mechanism by which the tensile stress can be distributed to the uncracked concrete in the tension zone thereby improving its performance. This enables the section to work more efficiently and produce a tension stiffening effect. As a result concrete can contribute to the moment of inertia and the flexural rigidity of the section.

Before yielding, the tensile component in flexure is shared between the steel reinforcement and the external plate reinforcement. The concrete beneath the neutral axis also contributes to tension carrying capacity due to the stiffening effect from both the internal steel reinforcement and external plate reinforcement. As a result of the increased beam stiffness and since the internal steel reinforcement is carrying a lower proportion of the tensile component for a given applied load, the yield stress of the steel is reached at higher load levels when the plate is bonded to the beam. The externally bonded plate relieves some of the tensile stress carried by the internal steel reinforcement. This is structurally significant as the reinforcing bar strain controls the crack width in concrete.

After yielding, the externally bonded plate continues to support the tensile component of the couple acting on the section. Hence the reduction in flexural rigidity is significantly less than when the beam is unplated. The plate is able to support an increasing tensile bending component and the plated beams can sustain considerably higher applied loads before collapse occurs. 


\section{Effect of GFRP plating on failure mode and crack pattern}

The test beams experienced considerable flexural cracking and vertical deflection near to failure. Well distributed closely spaced cracking was observed. None of the beams exhibited sudden catastrophic failure. The randomly oriented fibres crossing the cracked section resisted the propagation of cracks and separation of the section. Flexural cracks are initiated in the constant moment region as the tensile strength of concrete is reached. The cracks propagate upwards as loading progresses but remain very narrow throughout the loading history and significantly smaller than those in the strengthened beams. This demonstrates the restraining effect caused by the laminate on crack openings.

It is evident that the steel fibre reinforced concrete beams exhibit more number of cracks with lesser widths at all load levels when compared with the reference beam. The reduction in crack width is directly related to increase in fibre content. In all the beams the flexural cracks were observed. These observed cracks were observed mostly in constant moment region. The crack propagate upwards as loading progress but remain narrow throughout the loading history and are significantly smaller than that in the reference beam. Well distributed closely spaced cracking was observed. Average crack widths were measured in the middle third regions using a crack detection microscope of $0.02 \mathrm{~mm}$ precision. The reduction in crack width was found to be $58.33 \%$ at ultimate load level for beams with $1.5 \%$ fibre content and strengthened with 5mmUDCGFRP laminate.

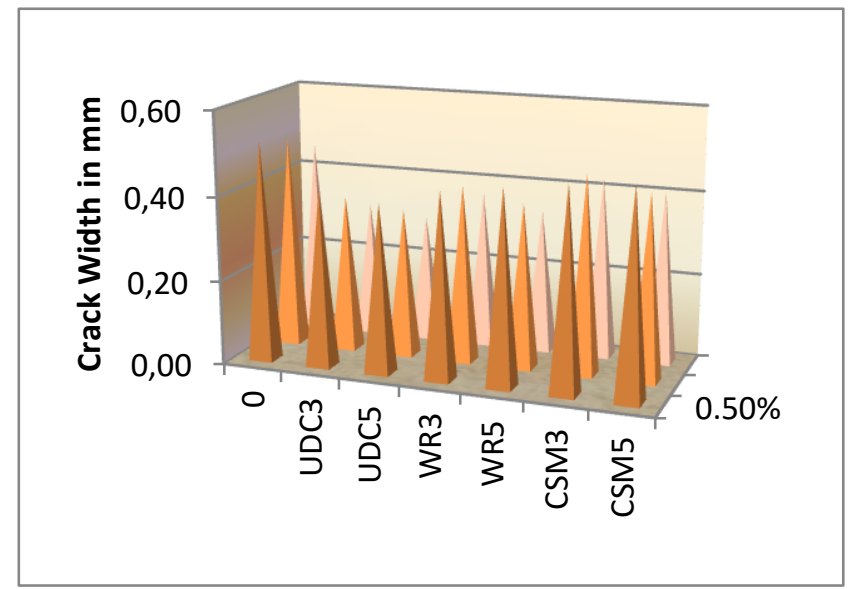

Fig. 7 Crack Width at Ultimate Stage

\section{Effect of GFRP plating on Ductility}

Ductility of reinforced concrete beams is essentially a measure of their energy absorption capacity. Ductility of a beam is its ability to sustain inelastic deformation without any loss in its load carrying capacity, prior to failure. Ductility can be expressed in terms of deformation or energy. The deformation can be deflection, strain or curvature. The load-deflection curves (Figs. 4 to 6) reveal that strengthening by bonding GFRP laminates positively influence the overall structural ductility of the strengthened beams. It can be readily seen from these results shown in fig.8 that strengthening with GFRP laminates has appreciable effect on the structural ductility. The strengthened beams (5mmUDCGFRP) exhibit an increase of $67.75 \%$ with $1.5 \%$ fibre content with respect to the reference specimens. 


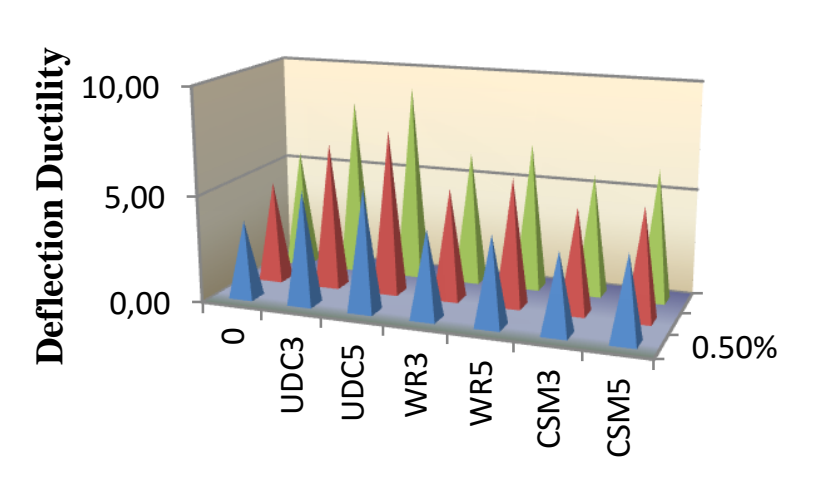

Fig. 8 Effect of GFRP Plating on Deflection Ductility of Beams

\section{ANALYTICAL STUDY}

The nominal flexural strength of the section with FRP external reinforcement can be computed from equation 9.11 of ACI 440.2R. An additional reduction factor $\psi_{\mathrm{f}}$ is applied to the flexural- strength contribution of the FRP reinforcement. A factor $\psi_{\mathrm{f}}=0.85$ is recommended by ACI 440.2.R. The internal strain and stress distribution for a rectangular section under flexure at ultimate stage is shown in Fig.9. The experimental results were compared with predictions made from equation 4.1.

$M n=A s f s\left(d-\beta_{1} \frac{C}{2}\right)+\psi_{f} A_{f} f_{f e}\left(h-\beta_{1} \frac{C}{2}\right)+\sigma_{c} b(h-e)\left(\frac{h}{2}+\frac{e}{2}-\frac{a}{2}\right)$

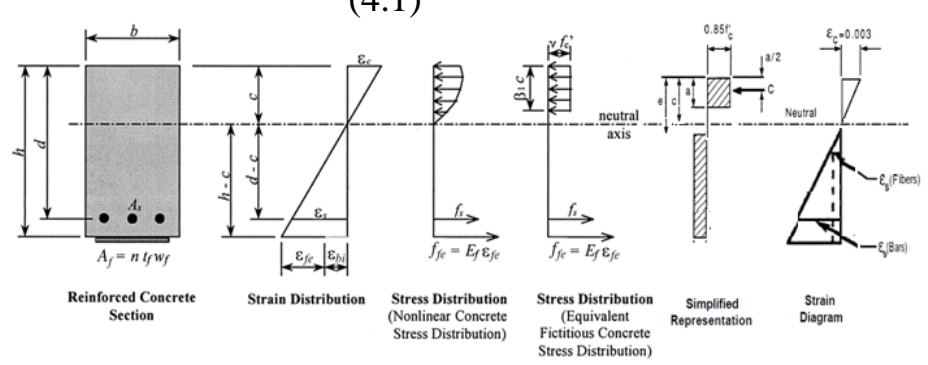

Fig.9 Internal Strain and Stress Distribution for a Rectangular Section under Flexure at Ultimate stage.

The results obtained from experiments agree well with the predictions obtained from ACI 440.2Requations. Fig.10 shows the Comparison of Experimental Results with ACI Prediction for FRP strengthened RC beams.

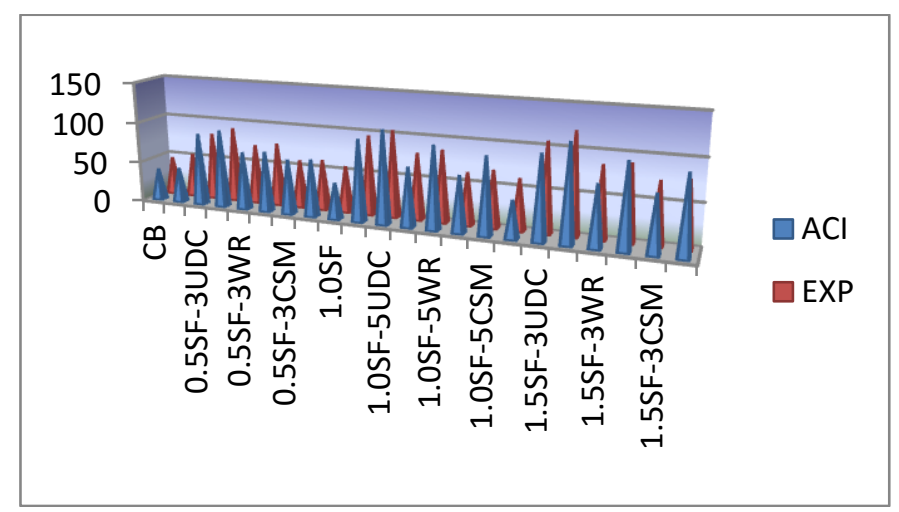

Fig.10 Comparison of Experimental Results with ACI Prediction 
SFRC Beams strengthened with GFRP Laminates

\section{CONCLUSION}

The epoxy bonding of GFRP laminates offers an attractive means of strengthening SFRC beams in flexure. Based on the results obtained from laboratory experiments, modeling with artificial neural network, regression analysis, reliability analysis, ACI Predictions and their discussions, the following conclusions are drawn.

1. GFRP laminates properly bonded to the tension face of SFRC beams can enhance the flexural strength capacity substantially. The maximum increase in ultimate load was found to be $61.01 \%$ with $1.5 \%$ fibre content strengthened with 5mmUDCGFRP laminates.

2. At any given load level, the deflections and the crack widths in the strengthened beams are reduced significantly compared to the unstrengthened beams. At the ultimate load level of the reference specimens, strengthened beams exhibit a decrease of deflection upto $68.33 \%$ with 5mmUDCGFRP laminates and a decrease in crack width upto $30.55 \%$.

3. All the beams strengthened with GFRP laminates experienced flexural failure. None of the beams exhibit premature failure of the laminate. An examination of the crack distribution indicates that the size and density of cracks are less in the strengthened beams than in the unstrengthened ones.

4. The beams strengthened with externally bonded GFRP laminates provide adequate ductility to ensure a ductile mode of failure. The strengthened beams exhibit an increase of $67.75 \%$ with $1.5 \%$ fibre content strengthened with $5 \mathrm{mmUDCGFRP}$ with respect to the reference specimens.

5. The ultimate loads obtained from experiments agree well with the values predicted using ACI equation.

\section{REFERENCES}

1. Choi, E., N. Utui and H.S. Kim, 2012. Experimental and analytical investigations on debonding of hybrid FRPs for flexural strengthening of RC beams. Comp.: Part B., 45: 248-256. DOI: 10.1016/j.compositesb.2012.06.022

2. Dong, J.F., Q.Y. Wang and Z.W. Guan, 2012. Structural behavior of RC beams externally strengthened with FRP sheets under fatigue and monotonic loading. Eng. Struct., 41: 24-33. DOI: 10.1016/j.engstruct.2012.03.024

3. Nadeem A. Siddiqui (2009), Experimental Investigation of RC Beams Strengthened with Externally Bonded FRP composites, Latin American Journal of Solids and structures, 6, 343-362.

4. Ceroni, F., 2010. Experimental performances of RC beams strengthened with FRP materials. Constr. Build. Mater., 24: 1547-1559. DOI: 10.1016/j.conbuildmat.2010.03.008

5. Huanzi, W. and A. Belarbi, 2011. Ductility characteristics of fiber-reinforcedconcrete beams reinforced with FRP rebars. Constr. Buil. Mater., 25: 2391-2401. DOI:10.1016/j.conbuildmat.2010.11.040

6. Singh, S.P., Y.Mohammadi and S.K.Kaushik, 2005. Flexural Fatigue Analysis of Steel Fibrous concrete containing mixed fibres. ACI Mater. J., 102(6): 438-444.

7. Banitha, N. and S.M. Soleimani, 2005. Fiber Synergy in Fibre-Reinforced selfconsolidating concrete, ACI Mater. J., 101(6): 508-517.

8. El-Amooury, T., and Ghobarah, A., "Seismic rehabilitation of beam-column joint using GFRP sheets", Engineering Structures, 24(11), 2002, 1397-1407.

9. Abdelhady Honsy., Hamdy Shaheen., Amr Abdelrahma., and Tamer Elafandy., "Performance of reinforced concrete beams strengthened by hybrid FRP laminates," Cement \& Concrete Composites, 28, 2006, 906-913. 
10. Li, L.J., Guo, Y.C., and Bungey, J.H., "An experimental and numerical study of the effect of thickness and length of CFRP on performance of repaired reinforced concrete beams," Construction and Building Materials, 20 (2006), pp. 901-909.

11. Attari, N., S. Amziane and M. Chemrouk, 2008. Strengthening reinforced concrete beams using hybrid FRP laminates. Proceedings of the $4^{\text {th }}$ International Conference on FRP Composites in Civil Engineering, Jul. 22-24, Zurich, Swizerland.

12. Swamy, N., Mukhopadhyaya, P., and Lynsdale, C "Ductility Consideration in Using GFRP sheets to strengthen and Upgrade structures", Proceedings of the Third International Symposium on Nonmetallic (FRP) Reinforcement for Concrete Structures, Sapporo, Japan. 1997, 637-644.

13. Banthia, N. and Soleimani, S.M.(2005), Flexural Response of Hybrid Fiber Reinforced Cementitious Composites, ACI Materials Journal, 102(5), 382-389.

14. Tarek H Almusallam and Yousef A Al-Salloum (2001), Ultimate strength Prediction for RC Beams Externally Strengthened by Composite Materials, Composites Part B: Engineering, 32, 609-619

15. Tarek H. Almusallam (2006), Load-Deflection Behavior of RC Beams Strengthened with GFRP Sheets subjected to Different Environmental Conditions, Cement and Concrete composite, 28(10), 879-889.

16. Toutanji, H., Zhao, L., and Zhang, Y. (2006), Flexural Behavior of Reinforced Concrete Beams Externally Strengthened with CFRP Sheets Bonded with an Inorganic Matrix, Engineering Structures, 28(4), 557-566.

17. ACI Committee 440 (1996), State-of-the-Art Report on Fiber Reinforced Plastic (FRP) Reinforcement for Concrete Structures, American Concrete Institute, Farmington Hills, Michingam, USA.

18. ACI Committee 540.4R-88 (1999), Design Considerations for Steel Fiber Reinforced Concrete, American Concrete Institute, Farmington Hills, Michingam, USA.

19. Barros, J.A.O., Dias, S.J.E., Lima, J.L.T (2007), Efficacy of CFRP - Based Techniques for the Flexural and Shear Strengthening of Concrete Beams, Journal Cement and Concrete Composites, 29(3), 203-217.

20. Wu Yao, Jie Li, Keru Wu (2003), Mechanical Properties of Hybrid FiberReinforced Concrete at Low Fiber Volume Fraction, Cement and Concrete Research, 33(1), 63-69.

Received: February 03, 2016; Accepted: July 14, 2016 